\title{
Indicadores para o novo serviço público: uma análise bibliométrica e sistêmica
}

Paloma Maria Santos

\begin{abstract}
Doutoranda em Engenharia e Gestão do Conhecimento pela Universidade Federal de Santa Catarina. Pesquisadora da Universidade Federal de Santa Catarina.
\end{abstract}

Paulo Maurício Selig

Doutor em Engenharia de Produção pela Universidade Federal de Santa Catarina (1993). Professor Associado da Universidade Federal de Santa Catarina.

http://dx.org/10.1590/1981-5344/1818

Este artigo objetiva investigar a ocorrência de trabalhos que exploram indicadores para o novo serviço público, por meio de uma análise bibliométrica e sistêmica. Utilizaramse cinco bases de dados de forma a localizar estudos sobre o tema no período de 1992 a 2012. Pôde-se constatar a carência e a insipiência de publicações sobre $o$ tema em questão, o que sugere a oportunidade e um relativo espaço para pesquisas futuras.

Palavras-chave: Análise Bibliométrica; Análise Sistêmica; Indicadores; Novo Serviço Público; Governança Democrática em Rede.

\section{Indicators for the new public service: a bibliometric and systemic analysis}

This article aims to investigate the occurrence of works that explore indicators for the new public service through a bibliometric and systemic analysis. It was used five databases in order to locate studies on the subject published from 1992 to 2012. It was found immaturity and lack of publications on the topic, suggesting opportunity and an open way for future research. 
Keywords: Bibliometric Analysis; Systemic Analysis; Indicators; New Public Service; Democratic Governance Network.

Recebido em 27.05.2013 Aceito em 09.07.2014

\section{Introdução}

O interesse pelo uso de indicadores de desempenho na administração pública tem sido uma constante nos últimos anos. Supõe-se que tal fato está ligado às pressões por um governo mais eficaz, eficiente, efetivo e, sobretudo, transparente aos cidadãos.

Esses são os preceitos da Nova Gestão Pública, movimento que surgiu em 1992 e que tem como foco a redução de gastos, o combate a corrupção e a melhoria na prestação de serviços, entre outras coisas. Essa abordagem, conforme afirmam alguns críticos, trata o cidadão como consumidor, bloqueando seu potencial participativo nos processos políticos decisórios.

Em resposta a Nova Gestão Pública, surge o Novo Serviço Público, com preceitos mais democráticos e responsivos. Uma abordagem que se constrói sobre a ideia do interesse público, da valorização do cidadão e do diálogo aberto, cujo estabelecimento de um espaço democrático para servir a sociedade apresenta-se como cerne da questão.

Nesse contexto, surge a preocupação em se verificar quais têm sido os instrumentos para medir o desempenho desses espaços democráticos e principalmente do Novo Serviço Público em si.

Pensando nisso, este artigo objetiva investigar a ocorrência de trabalhos que exploram indicadores para o novo serviço público, no contexto da governança democrática em rede, por meio de uma análise bibliométrica e sistêmica. Utilizaram-se cinco bases de dados (WebOfScience, SCOPUS, Emerald, Science Direct e Scielo) de forma a localizar estudos sobre o tema no período de 1992 a 2012.

$\mathrm{Na}$ seção 2 apresenta-se uma revisão sobre as bases teóricas da Nova Gestão Pública bem como do Novo Serviço Público. A seção 3 aborda o contexto no qual o Novo Serviço Público opera, qual seja a governança democrática em rede. Na seção 4 têm-se os principais conceitos sobre indicadores de desempenho. A seção 5 aborda os procedimentos metodológicos utilizados para a elaboração desta pesquisa. Na seção 6 têm-se os resultados e, finalmente, a seção 7 traz as considerações finais do artigo e as oportunidades de trabalhos futuros.

\section{A nova gestão pública e o novo serviço público}

Em decorrência das constantes pressões do mercado por um governo mais eficaz e enxuto, em especial, pelo efeito da crise fiscal 
ocorrida na década de 1970, surge, no contexto da administração pública, o que veio a ser chamado de Nova Gestão Pública ${ }^{1}$.

Esta abordagem, alicerçada no que alguns chamam de racionalismo econômico (DENHARDT, 2012), tem como fundamento o modelo clássico Weberiano de eficiência e autocontrole do sistema (SARKER, 2006).

A Nova Gestão Pública busca absorver as ideias do setor privado para o setor público, com foco na eficiência e no empreendorismo, centrando-se em resultados e promovendo a concorrência dentro e fora do governo. Seus objetivos primordiais envolvem a melhoria da prestação de serviços, a reforma do serviço civil, a reorganização das instituições, a racionalização da mão de obra, a descentralização, a redução de gastos e o combate a corrupção (SARKER, 2006).

Um esforço maciço para a sua utilização foi empreendido pelo governo dos Estados Unidos, durante a gestão de Bill Clinton e de seu então vice-presidente Al Gore, tendo em vista melhorar o desempenho do governo no nível federal. A partir de década de 1990, a Nova Gestão Pública passou a ser adotada em países como Estados Unidos, Inglaterra, Austrália, Canadá e Nova Zelândia (DENHARDT, 2012).

De acordo com Osborne e Gaebler (1995) os 10 princípios por trás da Nova Gestão Pública dizem respeito a um governo catalisador, próprio da comunidade, competitivo, movido por missões, orientado para resultados, voltado para seus consumidores, empreendedor, previdente, descencentralizado e orientado para o mercado.

As maiores críticas sobre essa abordagem, provavelmente resultante do empréstimo inadequado de valores advindos do setor privado, é que ela trata as pessoas como consumidores, usuários de um produto final, e não como cidadãos, parte de um processo de decisão política. Além disso, segundo Denhardt (2012), o movimento endossa ideias como a competição, a preferência por mecanismos de mercado para a decisão social e o lado "sombra" do empreendedorismo (traduzido pelo esforço da utilização dos recursos em prol da maximização da produtividade e da eficiência, o que pode por em risco a accountability).

Em resposta à Nova Gestão Pública, surge, no final de 1990, o Novo Serviço Público, cuja base epistemológica foi proposta por Janet e Robert Denhardt.

Diferentemente da Nova Gestão Pública, que se constrói sobre conceitos econômicos como a maximização do autointeresse, o Novo Serviço Público se constrói sobre a ideia do interesse público (resultado de um diálogo sobre os valores comuns), a ideia de administradores públicos a serviço dos cidadãos e, de fato, totalmente envolvidos com eles (DENHARDT, 2012).

O Novo Serviço Público, por conta desses preceitos, busca inspiração na teoria democrática, sobretudo pela sua preocupação com a conexão entre cidadãos e seus governos, e em abordagens que procedem de uma tradição mais humanística na teoria da administração pública,

\footnotetext{
${ }^{1}$ A teoria do New Public Management (Nova Gestão Pública) foi proposta em 1992 por David Osborne e Ted Gaebler em seu livro Reinventing Government.
} 
apresentadas como alternativas à gestão e ao design organizacional (DENHARDT, 2012).

Partindo desses temas, Denhardt e Denhardt (2003) elaboram sete princípios-chave para o Novo Serviço Público, quais sejam: servir cidadãos, não consumidores, perseguir o interesse público, dar mais valor à cidadania e ao serviço público do que ao empreendedorismo, pensar estrategicamente e agir democraticamente, reconhecer que a accountability não é simples; servir em vez de dirigir, e dar valor às pessoas, não apenas à produtividade.

Essa abordagem, que tem seu foco principal voltado para o espaço democrático da sociedade, requer cidadãos mais ativos, cidadãos na prática e não apenas no status (BARNETT, 2002), que estejam dispostos a exercer a sua cidadania. Não há direitos sem responsabilidades. Para Goldsmith e Eggers (2004), cidadãos engajados aceitam responsabilidades e participam das questões cívicas.

Segundo Denhardt (2012), o Novo Serviço Público opera no contexto de uma governança democrática em rede, tema da seção que segue.

\section{Governança democrática em rede}

Apesar de seu caráter abrangente, o conceito de governança está ligado a uma medida base da estabilidade e desempenho de uma sociedade (SARTORI, 2011), se referindo à maneira como as decisões são tomadas e como os cidadãos e os grupos participam do processo de formulação dos propósitos públicos e da implementação das políticas públicas (DENHARDT, 2012).

Já governança em rede, num conceito mais amplo, envolve uma articulação horizontal de interdependência, mas com atores funcionalmente autônomos, que interagem através de negociações ocorridas num ambiente relativamente institucionalizado, envolto por regras, normas, conhecimentos e imaginários sociais, que, por sua vez, são auto-reguladas dentro dos limites estabelecidos pelos mecanismos externos e que contribuem para a produção do propósito público no sentido amplo de visões, ideias, planos e regulamentos (SØRENSEN; TORFING, 2005).

Conforme ressalta Denhardt (2012), o processo de conciliação do governo hierárquico tradicional com as demandas por redes, construídas em linhas horizontais, se estabelece como sendo um dos desafios mais interessantes suscitados pela governança em rede.

Tendo em vista o crescente envolvimento de diversos grupos no desenvolvimento e na implementação da política pública, por meio das redes de governança, grande atenção tem sido voltada a entender os processos democráticos através dos quais essas redes se estabelecem, assim como o seu potencial para contribuição do fortalecimento da própria democracia (DENHARDT, 2012). 
Essa temática, segundo Sørensen e Torfing (2005), tem sido foco principal da agenda da nova geração de estudos sobre a teoria da governança em rede, que nos seus primórdios se apresentava com nomes diferentes, tais como corporativismo, economia negociada, heterarquia e policy networks. Enquanto que a primeira geração focou na eficiência das redes, a segunda foca na responsividade das mesmas.

A governança democrática em rede tem por base princípios de cooperação e colaboração de natureza não-hierárquica, onde as relações entre os participantes se dão horizontalmente, sem qualquer tipo de poder hierárquico estabelecido quando na formulação da política pública (WACHHAUS, 2009; DENHARDT, 2012).

A colaboração, dentro desse contexto, deve levar em conta cinco dimensões base, conforme Thomson e Perry (2006):

Governança: os participantes devem saber como tomar decisões conjuntamente sobre as regras que irão determinar suas atividades bem como precisam criar estruturas para se chegar a um acordo sobre as atividades e metas colaborativas, por meio de arranjos de poder compartilhado.

Administração: enfoca a necessidade de uma estrutura administrativa de suporte, clareza sobre funções e responsabilidades, capacidade de estabelecer limites, a presença de metas concretas alcançáveis e a boa comunicação.

Autonomia: trata do processo de conciliação entre os interesses individuais e os coletivos.

Mutualidade: enfatiza que o compartilhamento de informações, ainda que condição base para a colaboração, não é, por si só, suficiente para o seu sucesso. É preciso que haja benefícios para as partes envolvidas.

Confiança e reciprocidade: enfatiza a necessidade de se estabelecer condições de confiança mútua entre as partes envolvidas e ressalta que a reciprocidade é um fator chave para uma ação coletiva bem sucedida.

Segundo Sørensen e Torfing (2005), para melhorar o desempenho democrático da governança em rede é necessário que se fortaleça a ancoragem democrática dos políticos eleitos, a base dos membros de grupos participantes e organizações, a cidadania (territorialmente definida) e a própria democracia, com suas regras e termos de conduta.

Apesar de todos esses benefícios possíveis, vislumbrados a partir do estudo da governanca democrática em rede, o fato é que só poderemos apreciá-los plenamente se tivermos certeza de que a governança é mesmo democrática. 
Para esse fim, podem ser atribuídas medidas de desempenho, traduzidas pelos chamados indicadores de desempenho, tema abordado a seguir.

\section{Indicadores de desempenho}

Os indicadores podem ser entendidos como parâmetros que permitem mensurar as modificações nas características de um processo, sistema ou organização (DEPONTI; ECKERT; AZAMBUJA, 2002).

Eles devem ser expressos, sempre que possível, como uma relação que caracterize de fato um desempenho (rendimento ou performance). Assim, indicadores de desempenho devem estar associados a um sistema de planejamento de ações, caracterizando a situação ou estado de uma atividade ou processo em relação ao que foi previamente estabelecido (SENAI, 1996).

Como principais características, Kligerman et al (2007) salientam que os indicadores devem ser o mais específico possível à questão tratada; ser sensíveis a mudanças específicas nas condições de interesse; ser cientificamente confiáveis, ser imparcial e representativo das condições de interesse, além de propiciar o máximo de benefício e utilidade.

Segundo os autores,

os indicadores foram desenvolvidos devido à necessidade de tratar a informação, na forma original ou 'bruta', de modo a torná-la acessível, permitindo entender fenômenos complexos, tornando-os quantificáveis e compreensíves de maneira que possam ser analisados, utilizados e transmitidos aos diversos níveis da sociedade, contribuindo com uma adequada planificação das políticas; e avançando na modernização institucional através da otimização do manejo das informações (KLIGERMAN et al, 2007, p. 200).

De acordo com Morales e Selig (2011), os indicadores de desempenho podem ser classificados de diversas formas. O Quadro 1 abaixo sintetiza os domínios referentes à função econômica, visibilidade e forma de construção. 
Quadro 1 - Diferentes classificações para os indicadores de desempenho

\begin{tabular}{|c|c|}
\hline Classificação segundo a: & Indicadores \\
\hline Função Econômica & Insumos \\
\hline Visibilidade & Produtos \\
\cline { 2 - 2 } & Eficiência \\
\hline Forma de construção & Efetividade \\
\hline & Eficácia \\
\hline & Simples \\
\hline & Relação \\
\hline & Índice \\
\hline
\end{tabular}

Fonte: Baseado em Morales e Selig (2011).

A utilização de indicadores no contexto do Novo Serviço Público é foco das pesquisas realizadas para o desenvolvimento desse artigo, cujos procedimentos metodológicos estão descritos na seção seguinte.

\section{Procedimentos metodológicos}

Este artigo utilizou o método de análise bibliométrica e análise sistêmica para investigação da ocorrência de estudos sobre indicadores para o novo serviço público, no contexto da governança democrática em rede.

A análise bibliométrica tem sido usada historicamente para rastrear citações em Journals acadêmicos. Em sua essência, ela busca realizar a contagem sobre conteúdos bibliográficos. Esse método pode auxiliar os pesquisadores durante o processo de tomada de decisão, pois permite explorar, organizar e analisar grande quantidade de dados, ajudando a encontrar padrões ocultos (DAIM et al, 2006).

Para Ensslin et al (2010a), a análise bibliométrica busca, por meio da contagem de documentos, evidenciar quantitativamente dados estatísticos advindos de um portfólio bibliográfico, tendo em vista a gestão da informação e do conhecimento científico e as possíveis indicações sobre a evolução da pesquisa em um determinado tema.

Já a análise sistêmica, foca no conteúdo das publicações. De acordo com Ensslin (2010b), esse método trata do processo científico utilizado para analisar uma amostra representativa de artigos de um dado tema de pesquisa, a partir de uma visão de mundo definida e explicitada por suas lentes, evidenciando os destaques e as oportunidades de conhecimentos encontrados na amostra, tanto para o assunto de pesquisa, quanto para cada lente e para a perspectiva estabelecida.

Com base nesses conceitos, este artigo partiu da seguinte pergunta de pesquisa: Quais trabalhos têm explorado o tema: "Indicadores para o novo serviço público"?

De acordo com as instruções de Sampaio e Mancini (2007), definiram-se as estratégias de busca, bem como os critérios de inclusão e exclusão dos artigos, conforme apresentado abaixo: 
Realização de uma busca utilizando os termos específicos "indicators" E "new public service" nas bases de dados WebOfScience, Scopus, Emerald, Science Direct e Scielo (pesquisas realizadas ao longo do mês de Janeiro/2012);

Seleção dos seguintes campos de busca e áreas de pesquisa:

\begin{tabular}{|lcl|}
\hline Base de dados & Campos de busca & \multicolumn{1}{c|}{$\begin{array}{c}\text { Areas selecionadas } \\
\text { WebOfScience }\end{array}$} \\
& Topic & $\begin{array}{l}\text { Public Administration, Management, Social } \\
\text { Sciences Interdisciplinary, Law, } \\
\text { Multidisciplinary Sciences, Business, } \\
\text { Education Educational Research }\end{array}$ \\
\hline Scopus & Abstract, Title, Keywords & $\begin{array}{l}\text { Social Sciences, Business, Management and } \\
\text { Accounting, Multidisciplinary }\end{array}$ \\
\hline Emerald & All fields (Match Phrase) & - \\
\hline Science Direct & Abstract, Title, Keywords & - \\
\hline Scielo & All indexes & - \\
\hline
\end{tabular}
2012;

Inclusão dos trabalhos publicados entre os anos de 1992-

Instrumento de coleta: exportação dos dados dos trabalhos resultantes da busca para o Endnote $x 5$.

Os critérios de seleção dos artigos envolvem a leitura do título, leitura resumo, disponibilidade do artigo completo na base e por fim, o conteúdo apresentado. Serão excluídos trabalhos cujo conteúdo efetivamente não responder a pergunta de pesquisa.

Aplicar-se-á, então, uma análise bibliométrica e sistêmica dos artigos que forem aprovados nos critérios acima estabelecidos. A análise bibliométrica buscará identificar: (a) principais autores; (b) palavraschave; (c) periódicos; e (d) artigos por ano, enquanto que a análise sistêmica elencará: (a) tipo de artigo; (b) principais conceitos; (c) metodologia; (d) mensuração; (d) resultados relevantes; e (e) recomendações futuras. A partir dessas indagações, se apresentarão quais lacunas que os autores deixam para pesquisas futuras.

A Figura 1 abaixo representa como se dará a aplicação dos procedimentos metodológicos aqui descritos. 
Figura 1 - Sequência da aplicação dos procedimentos metodológicos

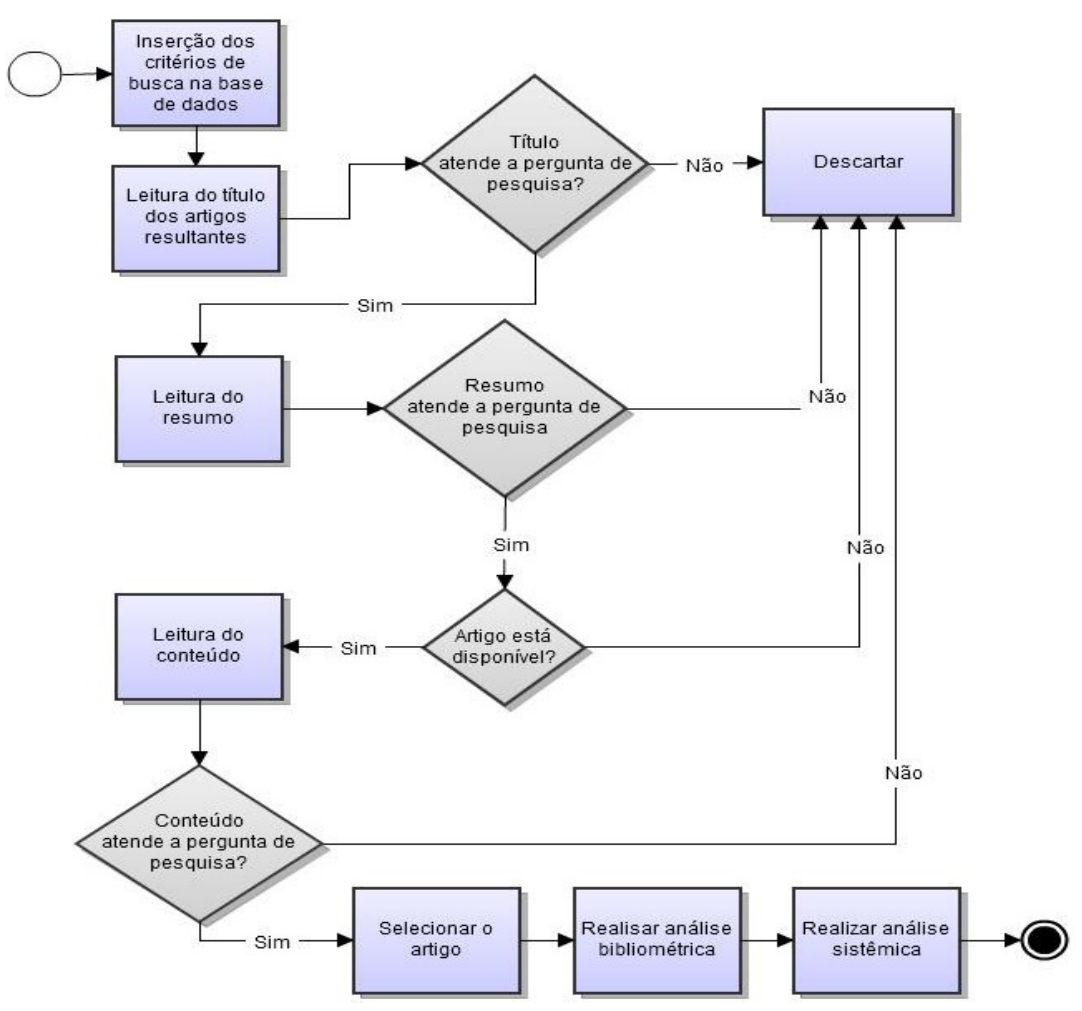

Fonte: Elaborada pelos autores.

Os resultados desses procedimentos metodológicos são apresentados na próxima seção deste artigo.

\section{Resultados da pesquisa}

Tendo em vista a quantidade de base de dados pesquisada, buscouse organizar em uma Tabela (Tabela 1) os resultados encontrados após a aplicação dos procedimentos metodológicos anteriormente descritos.

Tabela 1 - Resultados da pesquisa após a aplicação dos procedimentos metodológicos

\begin{tabular}{lcccc}
\hline Base de dados & $\begin{array}{c}\text { Artigos após a } \\
\text { aplicação das } \\
\text { estratégias de } \\
\text { busca }\end{array}$ & $\begin{array}{c}\text { Artigos } \\
\text { após leitura } \\
\text { do título }\end{array}$ & $\begin{array}{c}\text { Artigos após } \\
\text { leitura do } \\
\text { resumo }\end{array}$ & $\begin{array}{c}\text { Artigos após leitura do } \\
\text { conteúdo } \\
\text { (selecionados) }\end{array}$ \\
\hline WebOfScience & 31 & 8 & 4 & - \\
Scopus & $163^{*}$ & 9 & 5 & 1 \\
Emerald & 21 & 13 & 3 & 1 \\
Science Direct & 57 & 5 & 2 & - \\
Scielo & - & - & - & 2 \\
\hline Total & 246 & 35 & 14 & - \\
\hline
\end{tabular}


*26 desses eram repetidos

Fonte: Elaborada pelos autores.

Como se pode perceber, a base de dados que apresentou o maior número de resultados logo após a aplicação das estratégias de busca foi a Scopus, com 163 artigos (sendo que 26 já haviam sido recuperados pelas outras bases escolhidas). Já a base Scielo não apresentou nenhum trabalho com a incidência dos termos pesquisados.

Após a leitura do título, $14,22 \%$ dos artigos foram selecionados. Partindo para a leitura do resumo, restaram apenas 5,69\% do total encontrado (14 artigos). Eles foram lidos na íntegra e após a análise dos seus conteúdos, 2 foram escolhidos.

O fato é que nenhum dos dois artigos tratou exatamente do estabelecimento de Indicadores de Desempenho para o Novo Serviço Público, conforme veremos nas análises bibliométrica e sistêmica, apresentadas abaixo. Mas tais escolhas foram feitas por se entender que os artigos abordaram, como pano de fundo, a temática da participação democrática do cidadão frente às questões políticas, vindo a colaborar futuramente com a base de estudos necessárias para o desenvolvimento dos indicadores.

\subsection{Análise bibliométrica}

A análise bibliométrica buscou identificar os principais autores, palavras-chave, periódicos e a distribuição dos artigos por ano. Esses dimensionamentos estão dispostos no Quadro 2, abaixo.

Quadro 2 - Análise bibliométrica dos artigos escolhidos

\begin{tabular}{|c|c|c|c|}
\hline Principais autores & Palavras-chave & Periódicos & $\begin{array}{l}\text { Artigos por } \\
\text { ano }\end{array}$ \\
\hline $\begin{array}{l}\text { Tatiana Sotirakou } \\
\text { Mary Zeppou }\end{array}$ & $\begin{array}{l}\text { Knowledge management } \\
\text { Learning organizations } \\
\text { Public sector reform } \\
\text { Strategic management } \\
\text { Training } \\
\text { Organizational change }\end{array}$ & Management Decision & 2004 \\
\hline $\begin{array}{l}\text { Michael Bratton } \\
\text { Eric C. C. Chang }\end{array}$ & $\begin{array}{l}\text { Africa } \\
\text { Democracy } \\
\text { Governance } \\
\text { Public opinion } \\
\text { Rule of law } \\
\text { State }\end{array}$ & $\begin{array}{ll}\text { Comparative } & \text { Political } \\
\text { Studies } & \end{array}$ & 2006 \\
\hline
\end{tabular}

Fonte: Baseado em Sotirakou e Zeppou (2004) e Bratton e Chang (2006).

Apesar da proximidade do contexto em que essas palavras-chaves usualmente são utilizadas, nenhuma delas teve ocorrência simultânea nos dois trabalhos. Os periódicos também são diferentes, sendo um da área 
da Gestão (Management Decision - Não é analisado pelo JCR - Journal Citations Reports) e outro da área da Política (Comparative Political Studies - Fator de impacto de 1.813).

Usando o Journal Analyzer (ferramenta da Scopus para analisar Periódicos), procurou-se avaliar os dois periódicos, considerando $o$ prestígio da fonte $(S J R)^{2}$, calculado em função das citações ponderadas por documento; o impacto por paper (SNIP), que corrige as diferenças na freqüência de citação de diferentes campos de pesquisa; e o total de citações recebida pelo periódico no ano (Citations). Os resultados dessas extratificações estão dispostas nas Figuras 2, 3 e 4.

Figura 2 - SJR: Management Decision x Comparative Political Studies

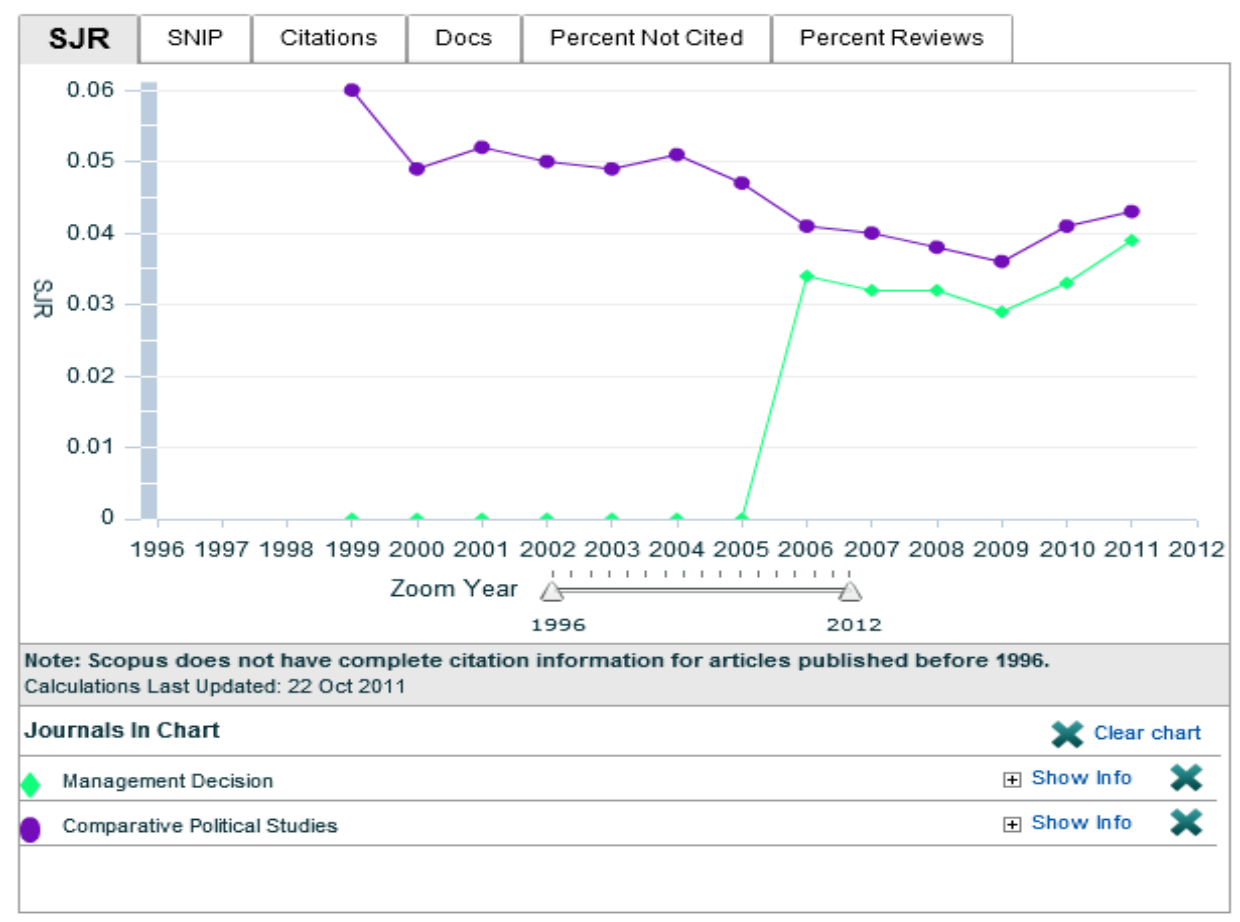

Fonte: Elaborada pelos autores.

\footnotetext{
${ }^{2} \mathrm{O}$ indicador SJR (SCImago Journal Rank) mede a influência científica de um periódico, considerando tanto o número de citações recebidas quanto o prestígio dos journals de ondem vêm as citações. Disponível em: http://www.info.sciverse.com/scopus/scopus-in-detail/tools/journalanalyzer. Acesso em 26 jan. 2012.
} 
Figura 3 - SNIP: Management Decision x Comparative Political Studies

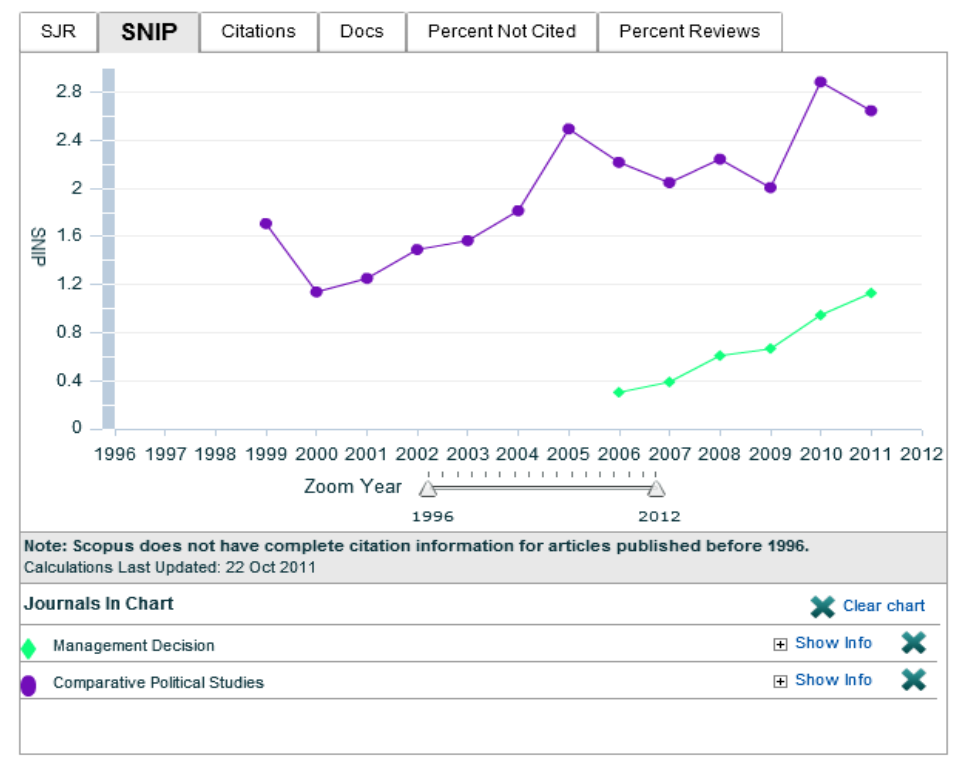

Fonte: Elaborada pelos autores.

Figura 4 - Citations: Management Decision x Comparative Political Studies

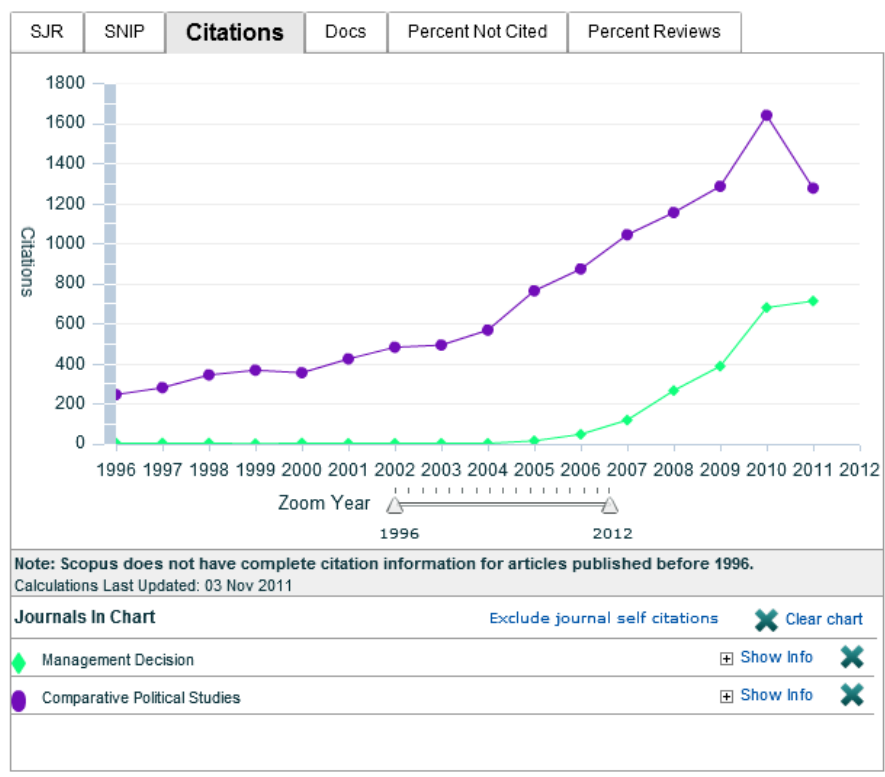

Fonte: Elaborada pelos autores.

Finda a análise bibliométrica, no item seguinte apresentar-se-á os resultados da análise sistêmica.

\subsection{Análise sistêmica}

A análise sistêmica deu-se em função da avaliação do conteúdo dos artigos escolhidos. Ela buscou elencar o tipo de artigo, os principais conceitos, a metodologia utilizada, os instrumentos de mensuração, os resultados relevantes apresentados e as recomendações futuras. A partir 


\section{dessas indagações se buscou, ainda, vislumbrar possíveis lacunas que os autores deixam para pesquisas futuras. Tais dimensionamentos estão apresentados no Quadro 3, na sequência.}

\section{Quadro 3 - Análise sistêmica dos artigos escolhidos}

\begin{tabular}{|c|c|c|}
\hline Artigo & $\begin{array}{l}\text { The "MATE" model: a strategic knowledge } \\
\text { management technique on the chessboard } \\
\text { of public-sector modernization }\end{array}$ & $\begin{array}{l}\text { State building and democratization in sub-saharan } \\
\text { Africa: Forwards, backwards, or together? }\end{array}$ \\
\hline Tipo de artigo & Research paper & Research paper \\
\hline Conceitos & $\begin{array}{l}\text { Acreditam que a modernização do setor } \\
\text { público está ligada à criação de uma } \\
\text { administração pública de aprendizagem, } \\
\text { que valorize o capital humano em sua } \\
\text { essência (o que ele pensa, aprende e como } \\
\text { se comporta), e que seja capaz de refletir } \\
\text { coletivamente, aprender como aprender, } \\
\text { desaprender velhas formas de fazer as } \\
\text { coisas e abandonar velhos hábitos }\end{array}$ & $\begin{array}{l}\text { Acreditam que um Estado capaz e legítimo não é } \\
\text { apenas uma pré-condição para a democracia bem } \\
\text { sucedida, mas é ele próprio também um produto dela. } \\
\text { A democracia introduz instituições que conectem os } \\
\text { cidadãos com o Estado e, enquanto isso, a } \\
\text { construção do Estado aumenta as capacidades para } \\
\text { melhorar o bem estar público, fortalecendo a } \\
\text { democracia. Seus elementos fundamentais são a } \\
\text { descentralização da autoridade governamental, } \\
\text { mobilização da sociedade civil, e o estabelecimento } \\
\text { de regras que regem a relação entre cidadãos e } \\
\text { Estado }\end{array}$ \\
\hline Metodologia & $\begin{array}{l}\text { Desenvolveram um framework de gestão do } \\
\text { conhecimento (MATE) e aplicaram em uma } \\
\text { organização pública na Grécia. O estudo de } \\
\text { caso baseou-se no monitoramento e análise } \\
\text { dos registros feitos durante a } \\
\text { implementação de cada uma das fases do } \\
\text { processo. Os autores serviram de } \\
\text { facilitadores no processo }\end{array}$ & $\begin{array}{l}\text { A partir dados do Afrobarômetro (série de pesquisas } \\
\text { comparativas de atitudes dos cidadãos face à } \\
\text { democracia, mercados e sociedade civil em } 18 \text { países } \\
\text { de África) e também de entrevistas coletadas com os } \\
\text { cidadãos, os autores buscaram analisar se existe uma } \\
\text { relação entre a construção do Estado e o } \\
\text { estabelecimento da democracia. Procuraram verificar } \\
\text { também qual dimensão da estaticidade é mais } \\
\text { importante }\end{array}$ \\
\hline Mensuração & $\begin{array}{l}\text { O modelo gira em torno da análise do } \\
\text { ambiente (interno e externo), do consenso } \\
\text { sobre os planos estratégicos e planos de } \\
\text { aplicação, da identificação e satisfação das } \\
\text { necessidades de formação organizacionais } \\
\text { e individuais e da avaliação constante e } \\
\text { reflexão sobre os resultados (feedback), } \\
\text { que realimenta o ciclo de desenvolvimento }\end{array}$ & $\begin{array}{l}\text { Usando indicadores da democracia (Freedom House: } \\
\text { dimensão dos direitos políticos e das liberdades civis) } \\
\text { e da governança (Banco Mundial: estabilidade } \\
\text { política, eficácia do governo, qualidade regulatória, } \\
\text { estado de direito e controle da corrupção - sendo a } \\
\text { estaticidade a média simples dos } 5 \text { indicadores) e } \\
\text { novos dados de opinião pública, os autores mostram } \\
\text { quais aspectos da construção do Estado são os mais } \\
\text { importantes. Adicionaram três dimensões na } \\
\text { avaliação da pesquisa: o alcance, a capacidade e a } \\
\text { legitimidade. Esses indicadores são empíricos, } \\
\text { derivados das observações dos autores e das } \\
\text { percepções dos cidadãos }\end{array}$ \\
\hline Resultados & $\begin{array}{l}\text { Por conta dos mapeamentos feitos durante } \\
\text { a aplicação do modelo na organização, foi } \\
\text { possível criar indicadores quantitativos e } \\
\text { qualitativos. Tornou-se evidente que o } \\
\text { processo de modernização requer um } \\
\text { amplo diálogo, colaboração, consenso, } \\
\text { autonomia e competência. Além disso, os } \\
\text { resultados confirmam que a aprendizagem } \\
\text { formal e informal (a nível individual e } \\
\text { organizacional) são prérequisitos para a } \\
\text { criação de conhecimento e criação da } \\
\text { organização de aprendizagem }\end{array}$ & $\begin{array}{l}\text { O alcance da infraestrutura do Estado e a entrega de } \\
\text { serviços de assistência social têm pouco impacto na } \\
\text { democratização, enquanto que o estabelecimento do } \\
\text { Estado de direito foi considerada crítica para a } \\
\text { construção da democracia. Embora a estaticidade } \\
\text { seja um requisito indispensável para a democracia, } \\
\text { não é uma condição suficiente. Os requisitos básicos } \\
\text { dizem respeito a um conjunto de estruturas estatais } \\
\text { que impõem a lei e a ordem, o respeito aos direitos } \\
\text { humanos, respostas às demandas populares, } \\
\text { governar por meios constitucionais, abrir espaços } \\
\text { para participação do cidadão e o controle a corrupção }\end{array}$ \\
\hline $\begin{array}{l}\text { Recomendações } \\
\text { futuras }\end{array}$ & $\begin{array}{l}\text { Aplicar o modelo em outros departamentos } \\
\text { dentro da mesma organização pública, a fim } \\
\text { de construir comunidades de profissionais } \\
\text { reflexivas, que cruzem as fronteiras } \\
\text { departamentais e se espalhem por toda a } \\
\text { organização. Além disso, reaplicar o modelo } \\
\text { em outras organizações }\end{array}$ & $\begin{array}{l}\text { A melhor maneira de seguir nos estudos futuros, tanto } \\
\text { para pesquisadores quanto para reformadores, é } \\
\text { reconectar o estudo dos estados de África com os } \\
\text { regimes políticos, para reconhecer a interação das } \\
\text { estruturas estatais e os procedimentos democráticos, } \\
\text { e promover a construção do Estado e da democracia } \\
\text { juntos }\end{array}$ \\
\hline $\begin{array}{l}\text { Lacunas para } \\
\text { pesquisas }\end{array}$ & $\begin{array}{l}\text { Desenvolver um modelo que considere a } \\
\text { participação do cidadão no processo de } \\
\text { modernização do Estado }\end{array}$ & $\begin{array}{l}\text { Verificar em que medida os países com o regime } \\
\text { democrático estabelecido, conseguem efetivamente } \\
\text { estabalecer mecanimos que permitam ampliar a } \\
\text { participação cidadã frente ao desenvolvimento e } \\
\text { implementação de políticas públicas }\end{array}$ \\
\hline
\end{tabular}

Fonte: Baseado em Sotirakou e Zeppou (2004) e Bratton e Chang (2006). 
A partir da análise sistêmica, pode-se perceber a importância que ambos os artigos dão para um Governo mais aberto, mais democrático, que persiga o interesse público, inserindo o cidadão no processo de desenvolvimento e implementação das políticas públicas.

Essa conexão entre cidadãos e seus governos é foco da teoria democrática que está por trás do Novo Serviço Público, como vimos no início deste artigo.

\section{Considerações finais}

Este artigo objetivou investigar a ocorrência de trabalhos que exploram indicadores para o novo serviço público, no contexto da governança democrática em rede, por meio de uma análise bibliométrica e sistêmica.

A utilização destes procedimentos permite vislumbrar um panorama das pesquisas científicas sobre um determinado tema, por meio da análise, coleta, classificação e manipulação da informação obtida nas bases de dados, objeto típico da área de ciência da informação.

Dessa forma, a organização e controle desses conteúdos de informação ajudam a encontrar padrões ocultos e evidenciam as oportunidades de pesquisas futuras, a partir da compreensão sobre o estado da arte do campo de pesquisa.

A partir das buscas efetuadas nas bases de dados, foi possível perceber que este tema ainda é bastante incipiente no âmbito das pesquisas acadêmicas, sendo a sua ocorrência vinculada apenas ao cenário onde a preocupação com a participação democrática do cidadão toma corpo.

Dessa forma, pode-se concluir que muito se fala a respeito do uso de indicadores no contexto da Nova Gestão Pública, que tem como ênfase medidas de eficiência e eficácia interna. Mas percebe-se que quando se avança para o contexto do Novo Serviço Público ou mesmo, em face mais ampla, da governança democrática em rede, com preceitos democráticos e responsivos, o cenário já é muito diferente. Assim, estas áreas abrem amplos caminhos para pesquisas futuras.

\section{Referências}

BARNETT, Neil J. Including ourselves: New Labour and engagement with public services. Management Decision, [S.I.], v. 40, n. 4, p. 310-317, 2002.

BRATTON, Michael; CHANG, Eric C. C. State building and democratization in sub-saharan Africa: Forwards, backwards, or together? Comparative Political Studies, [S.I.], v. 39, n. 9, p. 1059-1083, 2006.

DAIM, Tugrul U.; RUEDA, Guillermo; MARTIN, Hilary; GERDSRI, Pisek. Forecasting emerging technologies: use of bibliometrics and patent analysis. Technological Forecasting and Social Change, [S.I.], v. 73, p. 981-1012, 2006. 
DENHARDT, Janet V.; DENHARDT, Robert B. The New Public Service: serving, not steering. New York: M. E. Sharpe, 2003.

DENHARDT, Robert B. Teorias da administração pública. São Paulo: Cengage Learning, 2012.

DEPONTI, Cidonea M.; ECKERT, Córdula; AZAMBUJA, José L. B. de. Estratégia para construção de indicadores para avaliação da sustentabilidade e monitoramento de sistemas. Agroecologia e desenvolvimento rural sustentável, Porto Alegre, v. 3, n. 4, out/dez 2002.

ENSSLIN, Leonardo, ENSSLIN, Sandra R., LACERDA, Rogério T. de O.; TASCA, Jorge E. ProKnow-C (Knowledge Development ProcessConstructivist). Processo técnico com patente de registro pendente junto ao Instituto Nacional de Propriedade Industrial, Rio de Janeiro. 2010a.

ENSSLIN, Leonardo, ENSSLIN, Sandra R., LACERDA, Rogério T. de O.; TASCA, Jorge. E. Processo de Análise Sistêmica. Processo técnico com patente de registro pendente junto ao Instituto Nacional de Propriedade Industrial, Rio de Janeiro. 2010b.

GOLDSMITH, Stephen; EGGERS, Willian D. Governing by network. Washington, DC: Brookings Institution, 2004.

KLIGERMAN, Débora C.; VILELA, Heliana; CARDOSO, Telma A. de O.; COHEN, Simone C.; SOUSA, Denise; LA ROVERE, Emilio. Sistemas de indicadores de saúde e ambiente em instituições de saúde. Ciência e Saúde Coletiva, Rio de Janeiro, v. 12, n. 1, p.199-211, 2007.

MORALES, Aran B. T.; SELIG, Paulo M. Indicadores de Desempenho. Florianópolis Programa de Pós-Graduação em Engenharia e Gestão do Conhecimento, Universidade Federal de Santa Catarina, 2011. Notas de aula.

OSBORNE, David; GAEBLER, Ted. Reinventando o governo: como o espírito empreendedor esta transformando o setor público. 7. ed. Brasília, DF: MH Comunicação, 1995.

SAMPAIO, Rosana F.; MANCINI, Marisa C. Estudos de revisão sistemática: um guia para Síntese criteriosa da evidência científica; Systematic review studies: a guide for careful synthesis of the scientific evidence. Revista Brasileira de Fisioterapia, São Carlos, v. 11, n. 1, p. 83-89, jan./fev. 2007.

SARKER, Abu E. New public management in developing countries: An analysis of success and failure with particular reference to Singapore and Bangladesh. International Journal of Public Sector Management, [S.I.], v. 19, n. 2, p. 180-203, 2006.

SARTORI, Rejane. Governança em agentes de fomento dos sistemas regionais de CT\&I. 2011. 238f. Tese (Doutorado) - Universidade Federal de Santa Catarina, Centro Tecnológico, Programa de Pós-Graduação em Engenharia e Gestão do Conhecimento, Florianópolis, 2011. 
SERVIÇO NACIONAL DA INDÚSTRIA. Indicadores de desempenho para as áreas de assistência técnica e tecnológica, informação tecnológica e processos de gestão pela qualidade. Rio de Janeiro, 1996.

SøRENSEN, Eva; TORFING, Jacob. The Democratic Anchorage of Governance Networks. Scandinavian Political Studies, [S.I.], v. 28, n. 3, p. 195-218, 2005.

SOTIRAKOU, Tatiana; ZEPPOU, Mary. The "MATE" model: a strategic knowledge management technique on the chessboard of public-sector modernization. Management Decision, [S.I.], v. 42, n. 1, p. 69-88, 2004.

THOMSON, Ann M.; PERRY, James L. Collaboration processes: inside the black box. Public Administration Review, [S.I.], v. 66, p. 20-32, 2006.

WACHHAUS, Aaron. Networks in contemporary public administration: a discourse analysis. Administrative Theory and Practice, [S.I.], v. 31, p. 59$77,2009$. 